\title{
El Fundamento Mítico de la (Des)Igualdad en la Politeia de Platón ${ }^{1}$
}

\author{
Jorge Espinoza Cáceres ${ }^{2}$ \\ Rommel Hernández ${ }^{3}$
}

\begin{abstract}
RESUMEN: El siguiente escrito ensaya una interpretación del rendimiento del mito de los metales expuesto por Platón en su diálogo llamado Politeia a propósito de la siguiente interrogación: ¿Cómo se constituye el orden social en la pólis platónica? Para responder a esta pregunta debemos esclarecernos respecto de: i) El papel de la educación en la constitución del orden social. ii) La correlación entre el mito de los metales y el orden social. iii) La constitución tripartita de la psykhế humana. Una vez aclarado estos distintos puntos podremos comprender la oculta pero significativa función del mito de los metales en la constitución del orden social platónico.
\end{abstract}

PALABRAS CLAVE: Platón. Educación. Psykhế. Mito. Orden social.

\section{INTRODUCCIÓN}

El presente escrito investiga la relación entre mito y orden social en la Politeia de Platón. Se propone una interpretación de la sugerente relación entre la constitución tripartita de la $p s y k h \bar{e}^{\frac{1}{4}}$ como principio sostenedor de la (des)igualdad natural en la arquitectura platónica con el enigmático relato del mito de los metales. Preguntamos ¡cuál es el papel que ocupa concretamente

\footnotetext{
${ }^{1}$ http://dx.doi.org/10.1590/S0101-317320150003000010

${ }^{2}$ Universidad Diego Portales, Instituto de Humanidades, Ejército 260, Santiago, Santiago, Chile. Universidad Cooperativa, Calle 18 No. 47 - 150, Torobajo Pasto, Narińo, Colombia. E -mail: morelli@ug.uchile.cl

${ }^{3}$ Universidad Cooperativa, Calle 18 No. 47 - 150, Torobajo Pasto, Nariño, Colombia. E-mail: romel. hernandez@campusucc.edu.co.

${ }^{4}$ Me resisto a traducir el término griego psykhế debido su compleja y rica polisemia que dicho término encierra en el mundo helénico, especialmente en la filosofía de Platón. Lo que pretendo en el siguiente texto es esclarecer parcialmente el basto sentido de este término griego en la arquitectura platónica de la Politeia circunscrita a nuestra problemática. Por lo tanto, el término se utilizará de ahora en adelante sólo en la transcripción del término original en griego: psykhé.
} 
el mito de los metales en la arquitectura de la Politeia ${ }^{5}$ ¿Es acaso un relato accesorio, prescindible en la arquitectura platónica? ¿Una simple traducción de la (des)igualdad natural de la psykhế? ¿Un gesto de cordialidad para los ciudadanos no-filósofos cuya particular (in)capacidad comprensiva les imposibilitaría comprender la verdadera naturaleza de la psykhế, las profundas raices del orden social? Nuestras interrogantes son varias, pero su potencia interrogativa puede encauzarse en la siguiente interrogación matriz: ¿Cómo se fundamenta la (des)igualdad natural en la pólis ${ }^{6}$ platónica? Desde ella cobran vigor las distintas interrogaciones anteriores. Desde ella brota nuestra propuesta interpretativa de la función del mito de los metales. Ensayamos, en definitiva, una lectura de la compleja relación entre la psykhế humana en tanto fundamento (¿iinfundado?) del orden social de la pólis y la "función" del mito de los metales. Estratégicamente el texto estará divido en cuatro momentos. En los tres primeros expondremos los distintos elementos necesarios para comprender la compleja cuestión de la (des)igualdad en Platón, para en un cuarto y último momento, interpretar la relación entre el mito de los metales y el orden social en la Politeia de Platón. Esquemáticamente el texto se dividirá en: 1. Breve introducción al orden social de la Pólis: el poder educativo de la música y la gimnasia. 2. Primera función del mito de los metales: La explicación del orden social. 3. La constitución tripartita de la psykhé. 4. ¿Segunda función del mito de los metales? Para mayor claridad en la exposición hemos decidido encauzar nuestra propuesta interpretativa al problema de la constitución de la (des)igualdad expuesto exclusivamente en las Politeia de Platón, sin ánimos de rebasar dicha fuente discursiva.

\section{Breve introducción al orden social de la Pólis: el poder educativo de LA MÚSICA Y LA GIMNASIA}

Nos interesa proponer una lectura sobre la "fundación" de la (des) igualdad platónica y su enigmática relación con el mito de los metales. Para ello consideramos necesario adentrarnos al contexto desde y mediante el cual este inaparente problema cobra sentido y relevancia. Dicho a grandes

\footnotetext{
${ }^{5}$ Cito principalmente de acuerdo a La República. Edición bilingüe. Madrid: Centro de Estudios Políticos y Constitucionales, 2006. En caso de remitir a otra fuente o de alterar ligeramente la traducción será indicado en su pie de página respectivo.

${ }^{6}$ Preservo el término en griego transcrito al castellano debido a las dificultades idiomáticas-conceptuales que éste implica, y que la mayoría de las veces se pierden u opacan mediante una forzosa e incorrecta traducción.
} 
rasgos, el proyecto fundamental de la Politeia de Platón es la comprensión de la justicia como un bien en sí mismo, y con ello - o por ello - la defensa del vivir justamente (357a). Es a partir principalmente de este propósito que la exposición del texto cobra distintos giros, matices y análisis que enriquecen la Politeia platónica. Pero semejante empresa no es en modo alguno algo fácil de abordar. ¿Cómo comprender lo que es la justicia en sí misma, y no sus distintos reflejos en los actos llamados justos? ¿Cómo sobrevolar la justicia particular, siempre cambiante, efímera de los actos justos hacia el cielo en donde anida la justicia en sí misma? Este es en parte el gran problema que tiene ante la vista Platón. Elevada dificultad protagonizada por su divino portavoz, Sócrates, quien en principio se ve sobrepasado, aturdido por semejante investigación. Para subsanar esta dificulta - esta humilde miopía - Platón, en boca de Sócrates propone un estratégico giro que traslada la investigación sobre la justicia en sí misma reflejada en los actos justos hacia una imaginada pólis justa, para a partir de ésta, introducirnos en la investigación de la justicia en sí misma. Sócrates le explica a su interlocutor Glaucón que:

La investigación [acerca de la justicia] que emprendemos no es de poca monta; antes bien, requiere, a mi entender, una persona de visión penetrante. Pero como nosotros carecemos de ella, me parece - dije - que lo mejor es seguir en esta indagación el método de aquel, que gozando de muy buena vista, recibe orden de leer desde lejos unas letras pequeñas [el hombre justo] y se da cuenta de entonces de que en algún otro lugar están reproducidas las mismas letras en tamańo mayor y sobre fondo mayor también [la pólis justa]. (368d).

A partir de este curioso giro metódico Sócrates comienza a erigir en un primer momento una pólis sana y armónica (368a-372c). La necesidad, nos dice Sócrates, es el fundamento de toda pólis. Sus habitantes, especializados en distintos oficios, se reúnen con vistas a intercambiar sus distintos productos. Dentro de esta primera Pólis sana, fecunda encontramos artesanos, comerciantes y asalariados (370c-372c). Pólis perfectamente armónica que rápida y sugestivamente es desplazada por la cimentación de una segunda pólis enferma: la pólis de los cerdos, la pólis febril. (372d y sig.). En esta segunda pólis, infectada por los excesos, la codicia y la gula, emerge la expansión, la invasión y con ello la guerra. Y si hay guerra, deben haber guerreros afirma Sócrates. Con la emergencia de la guerra Sócrates empieza la limpieza de esta nociva pólis formando a sus eminentes guerreros. ¿Qué características deben reunir nuestros guardianes-guerreros? Las siguientes según Sócrates: "hace falta 
que [los guardianes] sean amables para con sus conciudadanos, aunque fieros ante sus enemigos." (375c) Elevada exigencia, rara vez la naturaleza reúne en una misma persona mansedumbre y ferocidad. Cómo hemos de lograr esta anómala combinación, se preguntan Sócrates y Glaucón. ¿Cómo hemos de educar a nuestros guardianes para que reúnan ambas disímiles cualidades?

Ante esta perplejidad emerge el poder educativo (curativo) de la música y la gimnasia (410b-412a). La música permitiría cultivar la mansedumbre de nuestros guardianes así como fomentar su admiración por el orden y el aprendizaje (400-402a). Complementariamente, la gimnasia - cuyo revolucionario objetivo en Platón es cultivar la psykhế y no el cuerpo permitiría que nuestros guardianes cultivaran la ferocidad, conjuntamente con la agilidad y resistencia que todo buen guerrero requiere, jespecialmente nuestros guerreros! De tal modo que "al ejercitarse en la gimnasia y realizar sus ejercicios, lo hará atendiendo al elemento fogoso de su naturaleza y con intención de estimularlo, más bien que con vistas al mero vigor corporal." (410b) No olvidemos este poder de la educación en la constitución del orden social, puesto que más adelante volveremos a él para interrogarle por su rendimiento.

Una vez formados nuestros guardianes a través de la reunión de estos carácteres tan disímiles (¿tan poco naturales?) Platón señala tres clases de pruebas a las que ellos deberán ser sometidos. Las conocidas pruebas para formar nuestros perfectos gobernantes (archontes) ${ }^{7}$ (412b). Para este fin, los guardianes desde su más tierna infancia deberán ser puestos a prueba en punto a su resistencia a la violencia, a la persuasión y a la seducción de los placeres y temores. Los que salgan airosos de estas pruebas desde la nińez, hasta su madurez serán los que podrán y deberán gobernar (archein) la pólis imaginada. Se les conferirá la autoridad y se les honrará en la vida y en la muerte. Serán nuestros guardianes perfectos, nuestros gobernantes (archontes) (412b-413e). Por el contrario, los que no logren superar tan olímpicas pruebas, los que caigan en las tentaciones de los placeres, en las excitaciones de la violencia, deberán conformarse con obedecer a los guardianes perfectos, estableciendo con ello una segunda casta guerrera, los así llamados guardianes auxiliares. Luego de distinguir entre estos dos tipos cualitativamente distintos de guardianes

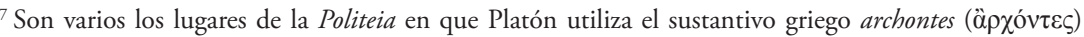
para referirse a las personas capaces de gobernar. Es natural que Platón emplease este término griego para referirse a los gobernantes ya que el verbo a partir del cual se construye el sustantivo archontes, (à $\rho(\omega)$, puede significar: dominar, gobernar, dirigir, guiar, mandar, etc. Destaco este término y sus distintas acepciones porque, como mostraré más adelante, tiene a mi entender un papel bastante significativo a propósito de la relación entre mito y orden social.
} 
(414a6) Sócrates introduce - con grandes recelos y desconfianza - una de esas falsedades necesarias que en 377 e ha prescrito $^{8}$ : el mito de los metales.

\section{Primera función Del Mito de los METAles: LA EXPLiCACión DEL ORDEN SOCIAL}

Pero escucha ahora el resto del mito. 'Sois, pues hermanos todos cuantos habitáis en la ciudad [pólis] - les diremos siguiendo con la fábula -; pero, al formaros los dioses, hicieron entrar oro en la composición de cuantos de vosotros están capacitados para mandar [archein], por lo cual valen más que ninguno; plata, en la de los auxiliares, y bronce y hierro, en la de los labradores y demás artesanos. Como todos procedéis del mismo origen, aunque generalmente ocurra que cada clase de ciudadanos engendre hijos semejantes a ellos, puede dar el caso de que nazca un hijo de plata de un padre de oro, o un hijo de oro de un padre de plata, o que se produzca cualquier otra combinación semejante entre las demás clases. Pues bien, el primero y principal mandato que tiene impuesto la divinidad sobre los magistrados ordena que, de todas las cosas en que deben comportarse como buenos guardianes, no haya ninguna a que dediquen mayor atención que a las combinaciones de metales de que están compuestas las psykhế s de los niños. Y si uno de éstos, aunque sea su propio hijo, tiene en la suya parte de bronce o hierro, el gobernante debe estimar su naturaleza en lo que realmente vale y relegarle, sin la más mínima conmiseración, a la clase de los artesanos y labradores. $\mathrm{O}$ al contrario, si nace de éstos un vástago que contenga oro o plata, debe apreciar también su valor y educarlo como guardián en el primer caso o como auxiliar en el segundo, pues según el oráculo, la ciudad [pólis] perecerá cuando la guarde el guardián de hierro o el de bronce. He aquí la fábula. (415 a y sig.).

He aquí, en gran parte, el relato del mito de los metales. He aquí en gran parte la explicación del orden social de la imaginada pólis platónica. Este mítico relato establece la estructura de la pólis en tres niveles distintos. En el nivel más bajo - del que apenas se refiere Platón a lo largo del texto - encontramos a los artesanos y labradores, es decir, a los distintos tipos de productores fundamentales para la constitución y funcionalidad de toda pólis. En el segundo nivel encontramos a la clase guerrera, los llamados guardianes

\footnotetext{
${ }^{8}$ A propósito de las falsedades necesarias prescritas anteriormente por Sócrates, Guthrie escribe lo siguiente: "Lo primero que hay que decir es que la palabra griega pseudos ('falso' y falsedad') no tiene necesariamente la implicación peyorativa de nuestro 'falso' o 'misterioso' [...] lo que Platón exige es que, aunque un mito sea inventado, pueda ser cierto en el sentido más profundo de nos desvirtuar el carácter divino o heroico [...] [Aunque] Sólo el gobernante entrenado puede emplear la falsedad y para el bien del Estado [Pólis]" GUTHRIE, W. K. C. Historia de la filosofía griega. Trad. esp. Álvaro Vallejo Campos y Alberto Medina González. Madrid: Gredos, 1990, v.4, p. 439.
} 
auxiliares que anteriormente hemos descrito cuya educación desde la tierna infancia estaba consagrada al estudio de la música y la gimnasia. Y por último (o primeramente) encontramos a nuestros valiosos gobernantes, a los guardianes perfectos. Observamos cristalizada en este mito toda la arquitectura platónica anteriormente descrita. Preguntamos entonces: ¿`cuál es el sentido que Platón designa a este mito si ya hemos establecido previamente este "anhelado" orden social? Si recordamos el estratégico giro de Sócrates de torcer su mirada a las letras grandes para ver mejor lo que - debido a nuestra miopía - se escapaba a nuestra mirada en las letras chicas (368d) comprenderemos que el ordenamiento social de la pólis responde al orden social de la naturaleza psiquica humana. ¡Gran reflejo de nuestra propia psykhế! Esta correlación entre la constitución del orden psíquico y el orden social de nuestra imaginada pólis justificaría el orden expositivo del propio Platón en su Politeia, quien, luego de introducir recelosamente el mito de los metales procede a constatar la justicia manifestada a gran escala en esta pólis ideal, para, en un segundo momento, lanzarse al encuentro de la justicia en el hombre justo. Esta interpretación del papel del mito de los metales coincidiría con las siguientes palabras socráticas: “¿No nos será absolutamente necesario - proseguí - el reconocer que en cada uno de nosotros se dan las mismas especies [eidế] y modos de ser que en la ciudad [pólis]? A ésta, en efecto, no llegan de ninguna otra parte sino de nosotros mismos." (435e) Ello coincidirá también con afirmaciones como las de Guthrie o de Cornford' ${ }^{9}$, quienes afirman que el orden social de la pólis descansa en el orden social de la psykhế platónica. En principio, el ordenamiento de nuestra pólis ideal, purificada ya de su febrilidad, sería el fiel reflejo del orden propio de toda naturaleza psíquica humana. De este modo, el orden de la exposición platónica sería inverso al orden de su fundamentación. Lo que funda propiamente a la pólis es la constitución psíquica, y el mito de los metales sería solamente la traducción de este profundo fundamento último de todo orden social. Pero ¿podemos pensar que el papel que desempeña el mito es sólo una explicación del orden social que refleja verdades más complejas, más profundas? En última instancia, ¿es este mito relato de una escondida y profunda

\footnotetext{
${ }^{9}$ Guthrie escribe a propósito del orden fundacional entra la psykhé y el ordenamiento de la pólis lo siguiente: "Este pseudos (414b), en forma mítica (415a), satisface la condición que Platón exige para que un mito sea aceptable [...] porque él mismo estaba convencido (como mostrará detalladamente después) de que la clasificación que simbolizaban los metales reflejaba la naturaleza humana y era psicológicamente correcta."( GUTHRIE, 1990, p. 443, pie de pág. 61). F. M. Cornford por su parte señala lo siguiente: "Coger la naturaleza humana individual tal y como la hallamos y construir un orden social que la hará lo mejor posible, tal y como ella es y como es probable que siga siendo." CORNFORD, F. M. The unwritten philosophy and other essays; edited with an introductory memoir by W. K. C. Guthrie. Cambridge: University Press, 1967, p. 58.
} 
verdad? Sospechamos que este orden social está fundado en un orden más verdadero, más profundo. Pero ¿cuál es este orden? ¿Es efectivamente el orden de la psykhế humana el que funda el orden social? ¿Sólo el orden psíquico?

\section{LA CONSTITUCIÓN TRIPARTITA DE LA PSYKHế}

Para responder a estas interrogantes debemos aclararnos respecto de cómo es la naturaleza psíquica caracterizada por Platón en la Politeia, y desde ella, comprender el orden fundacional entre la estructura del orden social y la constitución de la psykhế platónica. Para ello revisaremos principalmente la exposición explicita de la tripartición de la psykhế desplegada por Platón en el libro IV de la Politeia, esto es, desde 436a hasta 441c.

La tematización por parte de Platón de la tripartición de la psykhế es introducida a propósito del imaginario ordenamiento observado en la purificada pólis y su traducción al orden individual. Sócrates recuerda a su interlocutor Glaucón que la búsqueda de la justicia debe manifestarse necesariamente en el individuo:

Traslademos, pues, al individuo lo que allí se mostró [en la pólis imaginada], y si hay conformidad, será ello bueno, y si en el individuo aparece algo distinto, volveremos a la ciudad [pólis] a hacer la prueba, y así, mirando al uno junto a la otra, y poniéndolos en contacto y roce, quizás conseguiremos que brille la justicia como fuego de enjutos $y$, al hacerse visible, podremos afirmarla en nosotros mismo. (435a).

A partir de esta indicación por parte de Sócrates somos introducidos en el análisis de la psykhế humana. Pero este traslado hacia el análisis de la constitución de la psykhế por parte de Platón no deja de ser sugerente, llamativo, ya que presupone desde un principio la tripartición de la psykhée reflejada en el orden social anteriormente imaginado ${ }^{11}$. Sócrates aclara en las

\footnotetext{
${ }^{10}$ Resaltó mi desconfianza ante la clausura del fértil término platónico de psykhế a lo largo de la obra de Platón. Me parece reconocer distintas funciones, elementos y matices acerca de este término en obras tales como el Fedón, Fedro, Gorgias, Timeo, ya sean contradictorias o complementarias a la desarrollada por el mismo Platón en la Politeia.

${ }^{11}$ Me parece reconocer que el mismo Platón manifiesta su desconfianza a propósito del método de análisis de la psykhế. Justo antes de comenzar su análisis escribe lo siguiente: "Y has de saber, Glaucón, que, a mi parecer, con métodos tales como los que ahora venimos empleando en nuestra discusión no vamos a alcanzar nunca lo que nos proponemos pues el camino que a ello lleva es otro más largo y complicado aunque éste quizá no desmerezca de nuestras pláticas e investigaciones
} 
siguientes palabras que la tripartición de la psykhế es en parte evidente: “¿No nos será absolutamente necesario - proseguí - el reconocer que en cada uno de nosotros se dan las mismas especies [eidế] y modos de ser que en la ciudad [pólis]? A ésta, en efecto, no llegan de ninguna otra parte sino de nosotros mismos." (435e) De este modo, el problema de la constitución de la psykhế es atenuado. En principio, a Sócrates no le inquieta si la psykhế está o no constituida en estas tres partes, está triple constitución es clara, evidente, y por tanto, presupuesta; antes bien, lo que le preocupa a Sócrates, es la función que cada una de estas presupuestas - y por ahora desconocidas - partes [eidé] de la psykhế cumplen. El problema es más bien el siguiente:

Lo que ya es más difícil es saber si lo hacemos por medio de una sola especie o si, siendo éstas tres, hacemos cada cosa por una de ellas. ¿Entendemos con un cierto elemento, nos encolerizamos con otro distinto de los existentes en nosotros y apetecemos con un tercero los placeres de la comida y de la generación y otros parejos, o bien obramos con el psykhế [psykhế] entera en cada una de estas cosas, cuando nos ponemos a ello? (436b).

De este modo, el problema que tiene a la vista Platón es el de la composición de la psykhế, esto es, si la psykhế es unitaria o tripartita. ¿̨ero, qué quiere decir que la psykhế puede obrar enteramente? ¿Y cuáles son estas presupuestas partes compositivas de la psykhế? Antes de exponer los distintos elementos o partes compositivas de la psykhế humana Platón, por medio de Sócrates, establece el criterio para determinar la singularidad de cada uno de estos elementos, para de este modo, evitar la posible confusión de dos elementos distintos en uno mismo. El criterio para resolver este problema es el principio de no contradicción que Sócrates formula así:

Es claro que un mismo ser no admitirá el hacer o sufrir cosas contrarias al mismo tiempo, en la misma parte de sí mismo y con relación al mismo objeto; de modo que si hallamos que en dichos elementos ocurre eso, vendremos a saber que no son uno solo, sino varios. (436b-c).

A partir de este principio Sócrates procede a demostrar que la psykhế está constituida tripartitamente por tres elementos o partes: la parte racional

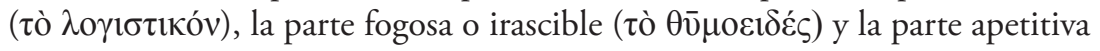

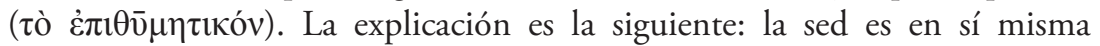

anteriores.” (435d) ¿¿A qué se debe la desconfianza de Platón? ¿¿ólo al método hasta ahora utilizado? ¿O tal vez a un conocimiento de poderes más ocultos, más insondables? 
simplemente un deseo de beber como tal; sin embargo, hay circunstancias en las que el mismo ser (humano) tiene sed, pero no está dispuesto a beber, o mejor dicho, prefiere no saciar su sed. Dado que nosotros no podemos atribuir el deseo y la contención al mismo elemento psíquico - de acuerdo al principio de no contradicción - la psykhế debe contener al menos dos elementos distintos, el apetito que desea beber, y la razón que juzga contener. La razón, de acuerdo al argumento platónico, sería la parte de la psykhé capaz de juzgar qué apetitos son beneficiosos para nosotros y cuáles no, posibilitando la contención del apetito, esto es, su dirección (archein). Más, algunas veces, la dirección de la razón es rebasada por el apetito y cedemos ante nuestros deseos aún considerándolos razonablemente perjudiciales en sí mismos. Estos peculiares pero cotidianos momentos de doblegación, de contrariedad de la razón por parte del apetito a veces nos encolerizan, nos contrarían, nos decepcionan. Ahora bien, si prestamos atención al suceso que agudamente Sócrates tiene a la vista para la determinación de la constitución de la psykhế podemos observar que se trata de sucesos en los que se juega esta peculiar contrariedad. Vale decir, que Platón no tiene precisamente a la vista los sucesos cotidianos en los que al parecer nuestra psykhế obra enteramente, como por ejemplo, cuando nuestra sed (apetito) reclama ser satisfecha y nuestra razón juzga que la complacencia de este apetito es un bien. En estos cotidianos sucesos nuestra psykhế nos parece que obra enteramente, es decir, que no está fragmentada, compuesta por distintos elementos. Nuestra psykhé nos parece armónica, y con ello, el suceso de la composición de la psykhé es opacado, silenciado. De este modo, nuestra psykhế puede obrar entera y armónicamente o bien puede obrar fragmentariamente, esto es, obrar de acuerdo a la parte apetitiva en conflicto con la parte racional, o viceversa. Es decir, la fragmentación de la psykhế no impide que ella misma a veces pueda actuar enteramente (precisamente en esto va a consistir la justicia de letras chicas, la justicia en el hombre: que la psykhé obre armónicamente, esto es, justamente.) Pero, ese es justamente el problema que quiere analizar Platón: la psykhé en contrariedad. Cuando emerge ese extraño suceso en que nuestros elementos psíquicos entran en contrariedad - cuando apetecemos algo pero al mismo tiempo lo rechazamos, nos contenemos -. Nos parece que este tipo de situaciones es decisivo a la hora de abordar el problema de la constitución del psykhế y su posible unidad o fragmentaridad. ${ }^{12}$ Que puede ser expresado de la

${ }^{12}$ Obsérvese el siguiente fragmento de Eric Brown en The Unity of the soul in Plato's Republic. "Socrates is not merely categorizing the kinds of psychological states and activities; he has already done that easy task (435d-436a). He now raises the hard question of whether we should attribute these 
siguiente manera: ¿Lo hacemos todo por medio de una sola especie - razonar, enfurecernos, apetecer - o más bien, si son tres, cada una de ellas cumple una función especial en nuestro comportamiento mundano? Ese es el problema en cuestión. Y, en cierto sentido se supone, se antepone la tripartición de la psykhế conjuntamente con este tipo de situaciones contrarias - a lo mejor esta tripartición Platón la había desarrollado con anterioridad, o más bien la había heredado - pero lo decisivo es que ésta supuesta tripartición es ella misma, a través de los distintos razonamientos expuestos por Platón, comprobada/ constatada.

Ahora bien, retomando el análisis platónico, Sócrates aclara que debido a que somos arrastrados por esta sensación de contrariedad tendemos comúnmente a confundir los apetitos con la cólera o fogosidad de la psykhế. Atribuyendo de este modo el efecto de la doblegación de la razón con su causa: el apetito. Pero estas "reacciones" de la psykhế contra nuestros propios apetitos, dice Sócrates, revelan que la fogosidad no es ella misma un apetito, sino más bien, un tercer elemento que a veces lucha contra ella y otras a favor de ella. Este último elemento de la psykhế sería según Platón el fogoso o irascible, que normalmente lucha como aliado de la razón para bien dirigir (archein) el apetito: "así habrá también un tercer [elemento] en la psykhế, el irascible, auxiliar por naturaleza del racional...” (441a) A partir entonces de esta explicación socrática tenemos la "constatación/corroboración" de los tres elementos constitutivos de la psykhế: la racional, la fogosa o irascible y la apetitiva o concupiscible.

Tenemos que la constitución tripartita de la psykhế de todo ser humano corresponde estructuralmente con el anhelado ordenamiento de nuestra imaginada polis ilustrada en el mito de los metales. Nuestra primera clase social, la de los "productores", reflejaría a la parte apetitiva de la psykhế. Así mismo, la segunda clase, la de los guerreros auxiliares, reflejaría a la parte irascible, y por último, la clase gobernante, la clase por excelencia reflejaría a la parte racional. De este modo, la estructura tripartita de la psykhế constituiría, y con ello, ordenaría a nuestra imaginada sociedad. El mito de los metales sería entonces una simple traducción de esta profunda verdad ${ }^{13}$.

different kinds to different causal sources in us." BARNEY, R.; BRENNAN, T. BRITTAIN, C. (Eds.). Plato and the divided Self. Cambridge: Cambridge University Press, 2012, p. 57.

${ }^{13}$ Destacó la siguiente observación desarrollada por José Manuel Pabón y Manuel Fernández-Galiano a propósito de la correlación entre las distintas clases sociales establecidas por el mito de los metales y los elementos constitutivos de la psykhế humana: "Se ha notado que la correspondencia entre dos elementos del alma [psykhế] y las tres clases de la ciudad [polis] quiebra un poco en este punto, 


\section{4. ¿̨Egunda FUnCión del Mito de Los Metales?}

Todo apunta a que la constitución del orden social de la pólis es un fiel reflejo del orden psíquico de todo ser humano. Las raíces del orden social anidarían en la psykhế humana y el mito de los metales sería la simple traducción de este orden tan profundo. Es decir, la (des)igualdad platónica hundiría sus raíces en lo más profundo del ser humano, en lo más oculto de nosotros mismos. Ante esta imaginada arquitectura platónica nos proponemos remover las exóticas raíces del orden social. Preguntamos: ¿cómo se constituye está (des)igualdad social, fiel reflejo del orden psíquico? En principio, esta interrogante me parece puede ser abordada desde tres distintas perspectivas, a través de tres criterios: i) a partir de

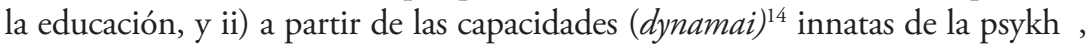
y iii) a partir de la combinación entre ambas. Respecto de i) la educación en principio la música y la gimnasia - se podría pensar que a partir de que algunos individuos no fueron educados - tal vez los artesanos - y los otros sí los guardianes, se establece esta (des)igualdad, es decir, que la constitución de la (des)igualdad depende de la educación. Pero esto no es tan claro, porque ¿̨cómo es posible afirmar que en las propias pruebas para seleccionar a los guardianes perfectos algunos las superen y otros no? ¿En qué consisten entonces estas capacidades "individuales" de la psykhế que permiten que algunos ciudadanos superan las pruebas y que otros las reprueben, tal y como lo expresa el mito de los metales? ¿Cómo se puede comprender entonces que algunos ciudadanos asciendan en el orden social y otros desciendan siendo igualmente educados? $\mathrm{Al}$ parecer, el poder de la educación no sería quien determina las capacidades de la psykhế, nos parece más bien que la educación estaría subordinada a estas capacidades innatas. Sólo a partir de ellas la educación puede jugar - como hemos visto en la constitución de los guardianes - un papel fundamental en la pólis platónica. Siguiendo la metáfora platónica, la educación pule el metal ya anteriormente fundado.

Ahora bien, respecto de ii) las capacidades (dynamai) innatas, el asunto parece ser más complejo. Porque el mismo Platón en varios pasajes enfatiza que la constitución de la psykhế es tripartita para cada individuo y sólo se limita a señalar que algunas personas son capaces de dominar (archein) a los apetitos y otras no, pero no específica en qué consiste esta "otra” capacidad,

porque la clase de los gobernantes no es sino una selección de la clase de los guardianes, mientras que lo racional no es una parte selecta de lo colérico, sino algo esencialmente diferente." Platón, 2006, p. 98, pie de página.

${ }^{14}$ ¿Debo resaltar que para el mundo helénico el verbo griego dynamai significaba ser capaz, poder, tener fuerza? 
ni cómo es posible a partir de nuestra igualitaria constitución natural de la psykhế semejante diferencia. ¿¿Se debe esto a que algunas personas tienen innatamente más desarrolladas su parte racional y otros su parte apetitiva? De ser así, de que originalmente nuestras capacidades sean distintas, ¿no estamos fundando nuestras capacidades en un orden anterior a todo orden, en un orden preestablecido? ¿De qué clase de orden es este orden? Y tal vez más confuso, ¿de qué clase es entonces el orden psíquico cuando asumimos que es natural que algunas personas innatamente puedan dominar los apetitos y otras no? Lo más sensato parece ser abordar la constitución de la (des)igualdad respecto a la compleja combinación entre educación y capacidades innatas. Pero esta combinación, nos parece, tampoco esclarecería cómo se constituye está (des)igualdad, al contrario, toparíamos con los mismos problemas anteriormente destacados y combinados, a saber, el innatismo de las capacidades $y$ sus irrastreables alteraciones. Reiteramos entonces ¿cómo se constituye esta (des)igualdad? ¿En qué se funda? ¿Es el orden psíquico en última instancia el fundamento del orden social?

Al parecer el problema de la constitución de la (des)igualdad en Platón no se logra solventar desde su propio orden psíquico, no claramente al menos, puesto que todo ser humano participaría de la triple constitución de la psykhế y el problema con el que topamos es precisamente ¿cómo es posible que a partir de esta igualitaria constitución de la psykhé sólo algunos ciudadanos puedan sobrepasar las olimpicas pruebas y ascender en las clases sociales y brillar como el oro? Destacamos que la educación no es suficiente para constituir la (des) igualda. Reconocimos que juega un papel relevante pero, en último término, la educación no constituiría el orden social, nos es suficiente por sí misma, más bien, ella responde ante este orden social, está al servicio de la constitución de este óptimo modelo. Ahora bien, si aceptamos estas limitaciones en el discurso platónico, podemos sostener que la constitución de la (des)igualdad desbordaría la propia constitución psíquico, y de este modo, el orden social estaría constituido por algo otro. Preguntamos ¿Quién es este orden otro? ¿Cómo se constituye la (des)igualdad en la imaginada pólis de la Politeia?

Nuestra propuesta es precisamente que esta constitución del orden social está sustentada por una fundación mítica. De este modo, el mito de los metales no sólo sería un relato accesorio en la arquitectura platónica, sino más bien su propio sustento, ¡un sustento de orden mítico! Nos parece que la sugerente introducción del análisis constitutivo de la psykhế y la funcionalidad de sus distintas partes, y con ello, su presupuesta, incuestionable tripartición psíquica 
es una inconsistencia de orden mitica. La pólis en última instancia reflejaría el mito de los metales, y no - como anteriormente sugerimos - respondería solamente a la estructura tripartita de la psykhế. ${ }^{15}$ El mito ordena, el mito funda, legitima la estructura de la pólis, así mismo como la estructura tripartita de la psykhế legitima, funda el orden social. Curiosa combinación entre mito y psykhế, en donde al menos hemos de reconocer la sugestiva participación del mito en el ordenamiento social. Mito y psykhế participarían activamente en la constitución de este orden social. Operando en profundos, ocultos niveles del ser humano para la conformación de su óptimo ordenamiento, ¡de su justo ordenamiento! Formando en bloque el ordenamiento social ${ }^{16}$.

Tal vez este complejo orden de fundamentación y relación de dependencia se debe a que el establecimiento del orden social, y con ello la fuerza de poder que preserva y vigila ese orden necesariamente está - o históricamente ha estado - ligado a una fundamentación mítica. Podríamos preguntar, pese al temor, a las vacilaciones de Sócrates para contar el mito de los metales expresadas en las siguientes líneas:

Me parece - dijo [Glaucón] - que no te atreves a relatarlo.

Ya verás cuando te cuente - repliqué [Sócrates] - cómo tengo razones para no atreverme [...] Voy, pues, a hablar, aunque no sé cómo ni con qué palabras osaré hacerlo, ni cómo he de intentar persuadir ante todo a los

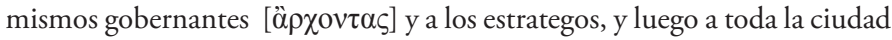
[pólis] entera. (414e).

${ }^{15}$ Como hemos destacado anteriormente, el análisis de la constitución de la psykhế es una aguda descripción de esos cotidianos, silenciosos momentos de contrariedad, de pugna "interior". Y por tanto, responden en gran medida, con sutil fidelidad a esos sucesos. Pero a su vez, dichos análisis presuponen una constitución de la psykhế anterior a ella misma, o mejor dicho, exigen un origen mítico. De este modo me parece que la descripción platónica de aquellos sucesos rebasa sus propios límites al pretender, más bien, al suponer su origen mítico, constriñendo la naturaleza humana psíquica y su carácter dinámico temporal.

${ }^{16}$ Esta hipótesis de lectura puede concordar armónicamente con distintos pasajes del Fedro en donde Platón expone la constitución inmortal de la psykhế del ser mortal (del ser humano) y su penosa reencarnación en el conocido precepto de Adastra (245c- 249e). "De entre todos estos casos, aquel que haya llevado una vida justa es participe de un mejor destino, y el que haya vivido injustamente, de uno peor. Porque allí mismo de donde partió no vuelve alma [psykhế] alguna antes de diez mil años - ya que no le salen alas antes de ese tiempo -, a no ser en el caso de aquel que haya filosofado sin engaño, o haya amado a los jóvenes con filosofía." (249a) Conforme a esta mítica exposición, la constitución del orden psíquico del ser humano estaría precedida, condiciona míticamente en tanto reencarnada. Conforme a sus méritos anteriores. No debemos olvidar la proximidad compositiva entre ambas obras. 
¿Por qué Platón prefiere arriesgarse y contar un relato que difícilmente podrían creer sus imaginarios ciudadanos? ¿Por qué esta necesidad del mito de los metales, esta persistencia del relato mítico? Se puede pensar una vez más esta función como decorativa, al servicio de la última de las clases sociales, la de los "productores", ya que ellos no tendrían la "capacidad" (¿la potencia?) para comprender el verdadero fundamento del orden social. En este caso, el mito de los metales estaría dirigido (educativamente dirigido) solamente para los ciudadanos de bronce. ¿Pero se podría pensar que los guerreros también requerirían esta explicación mítica tan difícil de creer en esos tiempos ${ }^{17}$ ? Se podría especular que sí, que el relato mítico sirve para convencer tanto al linaje "productor" como también al linaje de los guerreros auxiliares, no lo podemos asegurar, pero ¿se podría pensar que el mito podría cumplir alguna función persuasiva en los gobernantes? No son ellos precisamente los que tienen que distinguir entre las mentiras funcionales y las auténticas verdades, para, a partir de esta compleja diferenciación establecer el orden, el adecuado funcionamiento de la pólis, ya que ellos - sólo ellos - podrían, tendrían la capacidad (dynamai) de conocer lo que realmente es, las verdaderas razones (raíces) de este orden social. ¿O esta necesidad del mito de los metales responde a la antigua alianza entre orden y mito que Platón profundamente conocía? ¿Olvidamos que los gobernantes son los únicos capaces de guiar, de mandar, de dirigir? Capacidad que en griego se relaciona con la fuerza, con la potencia - por muy oscura o confusa o mítica que ésta sea. ¿Olvidamos que los gobernantes son los únicos capaces de bien dirigir (archein) sus volubles apetitos? En donde dirigir, mandar y guiar se entrecruzan y confunden en el propio término griego $\operatorname{archein}^{18}$. ¿Olvidamos que Platón apela a la alianza

${ }^{17}$ Considérese la siguiente observación de W.K.C. Guthrie (1990, v.4, p. 444) a propósito del rendimiento del mito de los metales en tanto instrumento de persuasión: "Sin embargo, a mediados del siglo quinto, la costumbre ateniense de llevar en el cabello cigarras doradas (símbolo de la autoctonía) era ya obsoleta, y no es sorprendente que tanto el mismo Sócrates como Glaucón sintieran serias dudas sobre las posibilidades de imponer el mito [ de los metales] a sus imaginarios ciudadanos [...] Puede ser que ellos sean pesimistas, porque esto no es algo que Sócrates desee que impongan a los demás los Guardianes y los gobernantes dotas de una sabiduría que todo lo ve: a él le gustaría sobre todo saber que ellos mismo [los Guardianes] lo creen (414c y d)."

${ }^{18}$ En nuestra querida lengua materna también se pueden aprecian, según creo, estas sugerentes alianzas entre poder, orden y mito. Según el diccionario de Ottorino Pianigniani guidare (guiar en castellano) proviene del gótico vitan, observar, vigilar y de la misma raíz que videre. Así mismo, de acuerdo al diccionario de Coromines, J. \& Pascual, J. A dirigir viene del latín (enderezar en una dirección, alinear, disponer, ordenar), formada del prefijo di- (divergencia múltiple) y el verbo regere. Es decir, denota disponer cada cosa en su dirección, dar órdenes en múltiple direcciones. A su vez el verbo latino regere viene de la raíz indoeuropea *reg- que está contenida también en latín en rex y regula, palabras que dieron rey y regla, y en germánico en el vocablo que nos proporcionó la palabra rico. La misma palabra 
psíquica entre la razón y la fogosidad, alianza entre razón y fuerza? ¿Conocía Platón esta vieja alianza entre mito, poder y orden? ¿Lamentaba esta vieja alianza? Pero tal vez todas estas interrogantes no son tan decisivas, tan urgentes como las siguientes: ¡el problema de la alianza entre poder, mito y orden social sólo se constrińe a la Politeia de Platón? ¿O rebasa dicha fuente discursiva? ¿O incluso sobrevuela al propio Platón hundiendo sus raíces en el propio devenir histórico de occidente? ¿Podemos pensar un orden social más allá de una mitificación del orden y de su poder?

CÁCERES, Jorge Espinoza; HERNÁNDEZ, Rommel. The mytical foundation of the (in) equality in Plato’s Politeia. Trans/Form/Ação, Marília, v. 38, n. 3, p. 155-170, Set./Dez., 2015.

\begin{abstract}
This article attempts an interpretation of the account of the myth of the metals as expounded by Plato in the Politeia. We address the following question: How is the social order established in the Platonic polis? To answer this question we must clarify: i) the role of education in the constitution of the social order; ii) the correlation between the myth of the metals and the social order; iii) the tripartite constitution of the human psyche. Once these various points have been made clear, we can understand the hidden but significant function of the myth of the metals in the constitution of the Platonic social order.
\end{abstract}

KEYWORDS: Plato. Education. Psyche. Myth. Social order.

\title{
REFERENCIAS
}

BARNEY, R.; BRENNAN, T.; BRITTAIN, C. (Eds.). Plato and the divided Self. Cambridge: Cambridge University Press, 2012.

BURNET, J. Platonis Opera. Oxford: Oxford University Press, 1900-1907. Recognovit brevique adnotatione critica Instruxit.

COROMINES, J.; PASCUAL, J. A. Diccionario crítico etimológico castellano e hispánico. Madrid: Gredos, 1991-1997.

CORNFORD, F. M. Plato’s Republic. London: Oxford University Press, 1941.

orden encierra en sí misma una sugestiva ambigüedad. Puede significar una buena disposición de las cosas entre sí, como a sí mismo una orden puede mentar, un mandato, una regla. COROMINES, J.; PASCUAL, J. A. Diccionario crítico etimológico castellano e hispánico. Madrid: Gredos, 1991-1997. 
The unwritten philosophy and other essays. Edited with an introductory memoir by W. K. C. Guthrie. Cambridge: Cambridge University Press, 1967.

DODDS, E.R. Los Griegos y lo irracional. Traducción María Araujo. Madrid: Alianza Editorial, 2001.

FERRARI, G.R.F. (Ed.). The Cambridge companion to Plato's Republic. Cambridge: Cambridge University Press, 2007.

GRUBE, G. M. A. El pensamiento de Platón. Traducción Tomás Clavo Martínez. Madrid: Gredos, 1987.

GUTHRIE W. K. C. Historia de la filosofía griega. Traducción Álvaro Vallejo Campos y Alberto Medina González. Madrid: Gredos, 1990. v. 4: Platón, el hombre y sus diálogos: periodo temprano.

PLATÓN. República. Traducción C. Eggers Lan. Madrid: Gredos, 1987.

. República. Traducción, notas y estudio preliminar José Manuel Pabón, Manuel Fernández-Galiano. Madrid: Centro de Estudios Políticos y Constitucionales, 2006. 